\title{
Energy, ecology and environment: a nexus perspective
}

\author{
Bin Chen ${ }^{1}$ \\ ${ }^{1}$ State Key Joint Laboratory of Environmental Simulation and Pollution Control, School of Environment, Beijing Normal University, \\ Beijing 100875, People's Republic of China
}

Published online: 26 February 2016

(c) Joint Center on Global Change and Earth System Science of the University of Maryland and Beijing Normal University and Springer-Verlag Berlin Heidelberg 2016

The rising concern about a potential global energy crisis and its impact on the economy and environment calls for a transition from the current development paradigms to a sustainable one. Such transition poses a significant challenge for scientists, industries and governments requiring innovative policies to save energy and reduce environmental and social impacts considerably. Moreover, the transition towards a low-carbon future needs to be cognizant of the social, cultural and institutional as well as the biophysical and geographical context within which it takes place and also in synergies provided by ecosystem services and technological regimes developing nature-inspired production and consumption systems. There is already plenty of literature on these problems, along with an abundance of journals with disciplinary territories and sharp boundaries on the intellectual landscape. However, we need a problem-oriented forum, transcending disciplinary boundaries, for putting the pieces together for promoting informed discussions of an integrated vision of a sustainable world.

The energy, ecology and environment (E3) issues, which are highly interwoven in the networks of human and natural systems, have been mostly disassembled into three separate aspects from a reductionist way of thinking, despite the trans-disciplinarity inherent in fundamental and applied research (Dincer and Rosen 2007; Jørgensen and Fath 2011; Sciubba and Zullo 2011; Chen 2014; Jørgensen et al. 2015). Efforts in one discipline without considering wider links and consequences often prove to be invalid when promoting sustainability. For example, the increased

Bin Chen

chenb@bnu.edu.cn use of energy may lead to potential environmental pollution and ecosystem degradation. Such trade-offs need linkage analyses and balanced solutions in an integrated way. Also, since national, regional and local systems are deeply embedded in globalized networks, distributed production activities have become key drivers behind global change imposing stress on ecosystems across spatial scale due to spatial linkages between local activities and remote impacts (Hubacek et al. 2014). Different from the previous integrated thinking, nexus is a useful metaphor to investigate mutual dependency of multiple elements in terms of coupled mechanism being interlinked and conversion processes embedded in intertwined disciplinary chains at multiple scales. As shown in Fig. 1, the E3 nexus, reassembling both the interwoven connections and teleconnections, is thus recommended as a new paradigm for tackling and resolving "wicked problems" (Chen 2015;

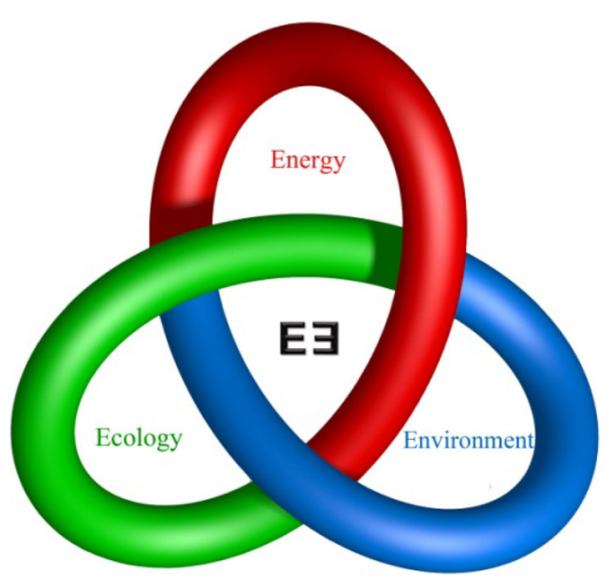

Fig. 1 Nexus of energy, ecology and environment 
Chen and Chen 2015). Actually, the nexus approach has gained momentum over the past decade and is expected to uncover more information on the broadening issues of climate change, energy and food security, socio-economic growth and resource management and avoid unintended and indirect consequences (Chen and Lu 2015; Costanza and Kubiszewski 2015; Yang and Chen 2016).

The list of problems that mankind is facing is very long, and all the problems are interrelated and cannot be solved separately and by one approach, but require an integrated approach based on the application of intra- and cross-disciplinary solutions. No single discipline has the capacity to cope with these kinds of complex issues that require the implications of different aspects of the sustainable development of the world. A surge of interests has thus led us to integrate the main disciplines as our development strategy in order to adapt our future to the irreversible changes inherent in the human civilization. The newly launched journal, Energy, Ecology \& Environment (E3), focuses on approaches that integrate considerations of energy, ecology and environment and uses this cross-disciplinary integration to be an important counterbalance towards the very dominating economic approach. Despite the growing concern on E3 nexus, there are still many obstacles to developing the tools and approaches at different scales. This journal may provide a cross-discipline forum to establish close links among these interrelated areas of investigation, set up systems science based on knowledge from other sciences and promote multidisciplinary solutions to tackle complex socio-economic and environmental problems.

\section{References}

Chen B (2014) Integration of energy, ecology and environment. Front Earth Sci 8(1):1-2

Chen B (2015) Integrated ecological modeling for sustainable urban metabolism and management. Ecol Model 318:1-4

Chen B, Chen SQ (2015) Urban metabolism and nexus. Ecol Inf 26:1-2

Chen B, Lu Y (2015) Urban nexus: a new paradigm for urban studies. Ecol Model 318:5-7

Costanza R, Kubiszewski I (2015) A nexus approach to urban and regional planning using the four capital model of ecological economics. In: Position paper for United Nations University, Institute for Integrated Management of Material Fluxes and of Resources (UNU-FLORES)

Dincer I, Rosen MA (2007) Exergy-energy, environment, and sustainable development. Elsevier, Oxford

Hubacek K, Feng K, Minx J, Pfister S, Zhou NJ (2014) Teleconnecting consumption to environmental impacts at multiple spatial scales-research frontiers in environmental footprinting. J Ind Ecol 18(1):7-9

Jørgensen SE, Fath B (2011) A new ecology—systems perspective. Elsevier, Oxford

Jørgensen SE, Marques JC, Nielsen SN (2015) Integrated environmental management: a transdisciplinary approach. CRC Press, Boca Raton

Sciubba E, Zullo F (2011) Is sustainability a thermodynamic concept? Int J Exergy 8(1):68-85

Yang J, Chen B (2016) Energy-water nexus of wind power generation systems. Appl Energy 169:1-13 